\title{
Medicina Caseira em sete localidades da região de Bauru, SP
}

* Faculdade de Medicina de Botucatu - UNESP.

* Curso de Aprimoramento (FUNDAP) no Departamento de Medicina em Saúde Pública, Facul. dade de Botucatu, UNESP.
Recebido para publicação em $12 / 03 / 86$.

\author{
Annichino, G.P.* \\ Imamura, C.R. de A. * \\ Mauad, M.A." \\ Medeiros, L.A. * \\ Morita, $I$. \\ Towata, E.A.*
}

Este trabalho foi realizado nas localidades de Duartina, Piratininga, Presidente Alves, Bocaina, Boracéia, Dois Córregos e Potunduva (Região de Bauru), em 1981.

$O$ objetivo foi avaliar o conhecimento e o uso de plantas medicinais, pela população.

Foram entrevistadas 372 pessoas, das quais, a maioria pertencia ao estrato social baixo.

Mais de 95\% das pessoas conheciam plantas medicinais, com grande utilização de duas a quatro variedades. $O$ não-uso representou, no total, apenas $10,8 \%$. O local de obtenção mais freqüente foi quintal, seguindo-se a farmácia. Citaram-se 118 plantas diferentes para uso medicinal. Destas, em apenas 9,3\% não se encontrou, na literatura, 0 nome cient ifico correspondente e, em 17,0\%, a indicação do valor medicinal. $O$ uso mencionado pelos entrevistados foi coincidente com os da literatura em quase $70 \%$ das vezes, em pelo menos um sintoma ou doença.

Discutiram-se as razões do recente incremento da medicina caseira; alguns aspectos referentes à industrialização e comercialização de plantas medicinais e sublinhou-se a necessidade de promoção de pesquisas farmacológicas para o melhor conhecimento do valor terapêtico da flora medicinal brasileira.

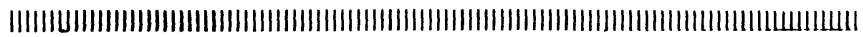

\section{INTRODUÇÃO}

A denominada "medicina popular" é constituída por práticas paralelas à "medicina oficial" dominante. Quem faz esta distinção é o sistema oficial de saúde, constatando sua existência e crescimento, a despeito de todo o avanço científico e tecnologico atual que tem o respaldo do saber científico e do sistema de produção ${ }^{7}$.

Entre as recomendações da Conferência de Alma-Ata Cadernos de Saúde Pública, R.J., 2(2):150-166, abr/jun, 1986 
sobre cuidados primários de saúde, há uma que diz respeito à práticas da medicina tradicional, que não podem ser desconhecidas; pelo contrário, devem ser incorporadas em determinados contextos sociais ${ }^{6}$.

Embora hoje já não se condene ou se reprima ostensiva. mente as práticas médicas populares, não se colocou ainda um ponto de partida para uma política que incorpore ao sistema oficial os conhecimentos da medicina popular, sem comercializá-los.

Entre os conhecimentos e práticas populares a serem assimilados pela medicina oficial, há aqueles relativos ao uso de plantas medicinais (medicina caseira). Ao longo da história da Medicina, em numerosas oportunidades, registrou-se a incorporação do emprego de vegetais para a cura de doenças, como por exemplo o caso da quinina, cujo uso veio dos índios peruanos, tendo entrado no receituário médico europeu, em 1632 com o nome de "casca do jesuíta", para tratamento da malária, depois denominada, por Linnaeus, de cinchona ${ }^{5}$.

Em relação à medicina caseira, se de um lado sabe-se que o uso de plantas sob a forma de chás, xaropes, óleos, infusões, ungüentos, etc, é difundido em nosso meio (embora pouco se pesquise a respeito, nas várias regiões do paŕs), de outro lado, é limitado o conhecimento acerca dos princípios ativos contidos em plantas medicinais. A farmacologia, neste campo, pouco tem investigado, talvez por falta de estímulo, de financiamento e de condições, além de provável bloqueio por parte da indústria farmacêutica, na qual a de capital estrangeiro detém $80 \%$ do mercado ${ }^{9}$.

De acordo com Carlini $^{9}$, a evolução da indústria química e farmacêtica fez com que a Medicina passasse a preferir substâncias puras sintéticas. Com isto, parte da cultura popular foi depreciada, houve descrédito sobre a terapêutica caseira com plantas e desestimulou-se a pesquisa necessária nessa linha. Além disso, a investigação científica com plantas exige, em primeiro lugar, a busca de informes sobre seu uso popular, para depois sucederem-se etapas de pesquisas químicas e farmacológicas, num processo muito demo. rado e consumindo elevadas somas de recursos financeiros.

A literatura médica brasileira, como já foi dito, é relativamente pobre em trabalhos publicados sobre usos, indicações e efeitos de plantas, registrando-se alguns livros ou coletâneas que os relacionam, com a toxonomia científica e popular das plantas $2,3,8,11,14,15,22,23,24$. Ravagnani ${ }^{22}$ realizou amplo estudo de vegetais de uso fitoterápico, em 95 locais do Estado de São Paulo, entre os quais, entretanto, não consta qualquer das localidades ou das microrregiões, objeto do presente trabalho.

No tocante ao uso de plantas medicinais e ds pesquisas 
farmacológicas nessa linha, recentemente registraram-se as seguintes posições oficiais: 1) a Organização Mundial da Saúde defende a necessidade de se tornar a essa utilização, mormente por parte da população que não tem acesso a drogas sintéticas ${ }^{1}$; 2) a $\mathrm{CEME}^{4}$, a FINEP ${ }^{20}$ e o $\mathrm{CNPq}^{18}$ estão apoiando pesquisas sobre a flora medicinal. Em Reunião Nacional de pesquisadores brasileiros, patrocinada pela OPAS, CNPq e Ministério da Saúde, em 1981, a investigação de substâncias presentes na flora medicinal brasileira foi considerada uma das prioridades ${ }^{13}$.

Considerando a atualidade do tema, inclusive suas implicações sociais, políticas e econômicas, o aparente retorno às raízes da terapêutica popular, a relativa escassez de trabalhos neste campo e, ainda a oportunidade que se apresentou de convívio de acadêmicos de medicina com a população de sete localidades da região de Bauru, em julho de 1981, julgou-se justificável a realização de pesquisa preliminar sobre o uso de medicina caseira nessas localidades que, inclusive, não foram abrangidas pela ampla pesquisa de Ravagnani ${ }^{22}$.

\section{OBJETIVOS}

A presente pesquisa tem os seguintes objetivos:

- colher informações sobre conhecimento e utilização de plantas medicinais, sobre os locais de sua obtenção e as indicações (finalidades) apontadas para o seu uso;

- relacionar informações obtidas com variáveis sócioeconômicas (estratos sociais).

\section{METODOLOGIA}

\section{Área de referência e época}

A pesquisa desenvolveu-se de 08 a 30 de julho de 1981, nos municípios de Dois Córregos, Bocaina, Piratininga, Duartina, Presidente Alves, Boracéia e Potunduva (distrito de Jaú), pertencentes à região de Bauru (7ạ Região Administrativa). Duartina, Piratininga e Presidente Alves pertencem à microrregião de Bauru, Bocaina, Boracéia e Dois Córregos, além do distrito de Potunduva, se incluem na microrregião de $\mathrm{Jaú}^{12}$.

A microrregião de Bauru constitui-se em elo entre as regiões agropecuárias de Mato Grosso e do oeste de São Paulo e os centros do litoral. Apresenta elevada densidade populacional e de transportes, além de expressivas atividades urbanas. O café sobressai ao sul, mas a economia já é agropastoril. A zona urbana de Bauru tem o setor terciário bastante desenvolvido. 
A microrregião de Jaú, limitada a leste por terras elevadas e a oeste pela garganta do Tietê, tem caráter agropastoril acusando expansão de cana e do amendoim, além de manter a lavoura do café. Jaú é centro de atividades industriais, nos setores têxtil, de vestuário e alimentar ${ }^{12}$.

No quadro abaixo, encontram-se as populações residen. tes, por localidade.

Populações residentes em sete localidades da região de Bauru

\begin{tabular}{llccr}
\hline \multirow{2}{*}{ Microrregião } & Localidade & \multicolumn{3}{c}{ População residente } \\
& & urbana & rural & total \\
\hline \multirow{3}{*}{ Bauru } & Duartina & 7436 & 4744 & 12180 \\
& Piratininga & 5833 & 4223 & 10056 \\
& Presidente Alves & 1821 & 3042 & 4863 \\
& & & & \\
Jaú & Bocaina & 4347 & 2440 & 6787 \\
& Boraceia & 1580 & 1973 & 3553 \\
& Dois Córregos & 12496 & 2983 & 15479 \\
& Potunduva (distrito) & 2571 & 3770 & 6341
\end{tabular}

Fonte: Fundação IBGE - Sinopse Preliminar do Censo Demográfico. Brasil; $99^{\circ}$ Recenseamento Geral do Brasil, 1980. Rio de Janeiro, 1981. Vol. 1 Tomo 1, no $18^{12}$.

\section{Casuŕstica e métodos}

Foram entrevistadas 372 pessoas, com a seguinte distribuição: Duartina: 63; Piratininga: 24; Presidente Alves: 61; Bocaina: 53; Boracéia: 33; Dois Córregos: 70; Potunduva (distrito): 68 .

As entrevistas foram realizadas por 15 alunos do $30^{\circ}$ ano da Faculdade de Medicina de Botucatu (UNESP) e 10 alunos de cursos superiores de Bauru, em diferentes locais: domicnlios, salas de espera de serviços de saúde, casas de comércio e jardins públicos, de forma circunstancial e sem criterio amostral. Em alguns casos, obteve-se indicação para procura de pessoas mais informadas sobre plantas caseiras. Os entrevistadores receberam um roteiro para orientação de abordagem e uma relação de critérios e normas para preen. chimento dos formulários.

Para anotação das informações, foi utilizado um formulário com questões abertas e fechadas sobre: município, ocupação principal, grau de instrução e renda mensal do chefe de familia; conhecimento e uso (finalidades) de plan. tas e ervas e fontes de obtenção de plantas. Os dados do formulário, exceto os referentes aos tipos e usos de plantas, 
foram depois transcritos em ficha codificada para processamento em computador.

Os critérios para a classificação das ocupações e dos estra. tos sociais foram os mesmos empregados por Marcondes et alii ${ }^{16}$. Como "omissos" foram classificadas pessoas das quais não se obtiveram dados suficientes para estratificação. 0 salário mínimo vigente na época era de Cr $\$ 8.560,00$ (oito mil, quinhentos e sessenta cruzeiros).

Os dados foram processados por computador do Centro de Computação e Informática (CCI) da Unesp, em Botucatu, através do programa SPSS (Statistical Package for the Social Sciences).

\section{RESULTADOS}

A distribuição das pessoas entrevistadas por estrato social apresentou grande concentração no estrato social baixo, com $69,8 \%$, e, a seguir, o médio baixo $(10,5 \%)$, médio alto $(5,6 \%)$ e o alto $(4,3 \%)$, num total de 372 pessoas. Como omissos foram classificados $9,7 \%$ das pessoas.

\section{TABELA 1}

Número de plantas medicinais utilizadas segundo o estrato social, em sete localidades da regiäo de Bauru, SP., 1981

\begin{tabular}{|c|c|c|c|c|c|c|c|c|c|c|c|c|}
\hline \multirow[b]{2}{*}{$\begin{array}{l}\mathrm{N}^{\mathrm{O}} \text { de } \\
\text { Plantass } \\
\text { Utilizadas }\end{array}$} & \multicolumn{2}{|c|}{ Alto } & \multicolumn{2}{|c|}{$\begin{array}{l}\text { Médio } \\
\text { Alto }\end{array}$} & \multicolumn{2}{|c|}{$\begin{array}{c}\text { Médio } \\
\text { Baixo }\end{array}$} & \multicolumn{2}{|c|}{ Baixo } & \multicolumn{2}{|c|}{ Omisso } & \multicolumn{2}{|c|}{ Total } \\
\hline & $\mathrm{N}$ & $\%$ & $\mathrm{~N}$ & $\%$ & $\mathrm{~N}$ & $\%$ & $\mathrm{~N}$ & $\%$ & $\mathrm{~N}$ & $\%$ & $\mathbf{N}$ & $\%$ \\
\hline $\begin{array}{l}\quad \begin{array}{c}1 \\
2-4 \\
5-9\end{array} \\
\text { Mais de } 10 \\
\text { Não usa } \\
\text { Não sabe }\end{array}$ & $\begin{array}{l}\overline{8} \\
3 \\
4 \\
1\end{array}$ & $\begin{array}{r}- \\
50,0 \\
18,8 \\
- \\
25,0 \\
6,3\end{array}$ & $\begin{array}{r}2 \\
11 \\
5 \\
1 \\
2 \\
-\end{array}$ & $\begin{array}{r}9,5 \\
52,4 \\
23,8 \\
4,8 \\
9,5 \\
-\end{array}$ & $\begin{array}{r}6 \\
20 \\
8 \\
- \\
4 \\
1\end{array}$ & $\begin{array}{r}15,4 \\
51,3 \\
20,5 \\
-\overline{3} \\
10,3 \\
2,6\end{array}$ & $\begin{array}{r}22 \\
127 \\
69 \\
8 \\
27 \\
7\end{array}$ & $\begin{array}{r}8,5 \\
48,8 \\
26,5 \\
3,1 \\
10,4 \\
2,7\end{array}$ & $\begin{array}{r}3 \\
20 \\
8 \\
1 \\
3 \\
1\end{array}$ & $\begin{array}{r}8,3 \\
56,6 \\
22,2 \\
2,8 \\
8,3 \\
, 28\end{array}$ & $\begin{array}{r}33 \\
186 \\
93 \\
10 \\
40 \\
10\end{array}$ & $\begin{array}{r}8,9 \\
50,0 \\
25,0 \\
2,7 \\
10,8 \\
2,7\end{array}$ \\
\hline Total & 16 & 100 & 21 & 100 & 39 & 100 & 260 & 100 & 36 & 100 & 372 & 100,0 \\
\hline
\end{tabular}

Quanto ao conhecimento de plantas medicinais, 95,4\% das pessoas responderam afirmativamente. Observou-se na tabela 1 que a grande maioria as utiliza, predominando em cada um dos estratos sociais o uso de duas a quatro plantas. A utilização de cinco a nove plantas foi também bastante referida, sendo a citação de mais de dez muito pouco significativa. $\mathrm{O}$ não-uso foi mais referido pelo estrato social alto. No total de 372 respostas, apenas $10,8 \%$ não utilizam plantas. 
$\mathrm{Na}$ tabela 2, observou-se que o quintal é o lugar mais mencionado como fonte de obtenção de plantas medicinais por cada um dos estratos sociais, predominando o estrato baixo. Em seguida, a farmácia, principalmente para o estrato médio baixo. A taxa de pessoas que citaram uma única fonte de obtenção foi de $56,5 \%$, enquanto que as que referiram mais de uma constituŕram apenas $16,6 \%$.

TABELA 2

Local de obtençāo de Plantas Medicinais segundo o estrato social, em sete localidades da Regiāo de Bauru, SP, 1981*

\begin{tabular}{|c|c|c|c|c|c|c|c|c|c|c|c|c|}
\hline \multirow{2}{*}{$\begin{array}{l}\begin{array}{l}\text { Estrato } \\
\text { Social }\end{array} \\
\text { le } \\
\text { tass } \\
\text { zadas }\end{array}$} & \multicolumn{2}{|c|}{ Alto } & \multicolumn{2}{|c|}{$\begin{array}{l}\text { Médio } \\
\text { Alto. }\end{array}$} & \multicolumn{2}{|c|}{$\begin{array}{l}\text { Médio } \\
\text { Baixo }\end{array}$} & \multicolumn{2}{|c|}{ Baixo } & \multicolumn{2}{|c|}{ Omisso } & \multicolumn{2}{|c|}{ Total } \\
\hline & $\mathbf{N}$ & $\%$ & $\mathbf{N}$ & $\%$ & $\mathbf{N}$ & $\%$ & $\mathbf{N}$ & $\%$ & $\mathbf{N}$ & $\%$ & $\mathrm{~N}$ & $\%$ \\
\hline $\begin{array}{l}\text { Quintal } \\
\text { Farmácia } \\
\text { Mato }\end{array}$ & $\begin{array}{l}8 \\
2 \\
3\end{array}$ & $\begin{array}{l}53,3 \\
13,3 \\
20,0\end{array}$ & $\begin{array}{r}14 \\
.5 \\
2\end{array}$ & $\begin{array}{r}56,0 \\
20,0 \\
8,0\end{array}$ & $\begin{array}{r}25 \\
13 \\
2\end{array}$ & $\begin{array}{r}56,9 \\
29,5 \\
4,5\end{array}$ & $\begin{array}{r}203 \\
25 \\
16\end{array}$ & $\begin{array}{r}73,0 \\
9,0 \\
5,8\end{array}$ & $\begin{array}{r}29 \\
1 \\
2\end{array}$ & $\begin{array}{r}82,7 \\
2,9 \\
5,7\end{array}$ & $\begin{array}{r}279 \\
46 \\
25\end{array}$ & $\begin{array}{r}70,3 \\
11,5 \\
6,3\end{array}$ \\
\hline $\begin{array}{l}\text { Feira ee } \\
\text { Quitanda }\end{array}$ & - & - & - & - & 2 & 4,5 & 6 & 2,1 & 1 & 2,9 & 9 & 2,3 \\
\hline $\begin{array}{l}\text { Outro } \\
\text { Não sabe }\end{array}$ & $\begin{array}{l}1 \\
1\end{array}$ & $\begin{array}{l}6,7 \\
6,7\end{array}$ & $\begin{array}{l}4 \\
-\end{array}$ & $\begin{array}{r}16,0 \\
-\end{array}$ & 2 & $\begin{array}{r}4,5 \\
-\end{array}$ & $\begin{array}{r}22 \\
6\end{array}$ & $\begin{array}{l}8,0 \\
2,1\end{array}$ & $\begin{array}{l}1 \\
1\end{array}$ & $\begin{array}{l}2,9 \\
2,9\end{array}$ & $\begin{array}{r}30 \\
8\end{array}$ & $\begin{array}{l}7,5 \\
2,1\end{array}$ \\
\hline Total & 15 & 100 & 25 & 100 & 44 & 100 & 278 & 100 & 35 & 100 & 397 & 100 \\
\hline
\end{tabular}

* Respostas múltiplas.

Com referência às plantas medicinais e seu uso referidos pelos entrevistados, o quadro 1 relaciona o nome citado (popular), o nome científico, o uso descrito na literatura e o mencionado nas entrevistas.

Para o total de 118 plantas diferentes citadas, não se encontrou o nome científico correspondente de apenas onze $(9,3 \%)$, e em vinte $(17,0 \%)$ a indicação do valor medicinal. Nestas últimas vinte plantas estão inclurdas as onze sem nomenclatura, enquanto que em nove havia o nome científico correspondente.

As plantas citadas com maior frequêencia foram: abacate, alecrim, alho arruda, boldo, camomila, canela, carqueja, chapéu de couro, erva-cidreira, erva-de-bicho, erva-doce, erva de Santa Maria, hortelã, laranja, limão, losna, mamão, marcelinha, poejo e quebra-pedra.

Nessa relação, verificou-se que o uso mencionado foi coincidente com o da literatura, em pelo menos um sintoma ou doença, em $69,4 \%$ das vezes. Exemplificaram essa concordância a erva quebra-pedra, o pacová, o poejo, oguaimbé, a alcachofra, a unha de vaca e o guaco, entre vários vegetais. 
Vinte e cinco plantas $(25,5 \%)$, todavia, não apresentaram uso coincidente, como por exemplo, a avenca, o mandacaru, o barbatimão e a quina. No caso da hortelã, a indicação para "dor de barriga" foi concordante, ao mesmo tempo em que seu uso como "calmante", nesta pesquisa, contrapôs-se ao de "excitante do SNC", segundo a literatura consultada. Em cinco oportunidades $(5,1 \%)$, a indicação referida pode ser considerada concordante de forma aproximada com a da literatura, como por exemplo, o "fedegoso", usado para maleita nas entrevistas e como antifebril no receituário pes. quisado, e a cana brava, respectivamente como anti-hipertensivo e diurético.

Verificou-se, também, que uma mesma planta teve indi. cações diversas, como foi o caso da erva-doce e a canela, e que determinados sintomas ou doenças costumam ser tra. tados por plantas de gênero e espécie diferentes, sendo um dos exemplos, a tosse, para a qual se indicaram o agrião, o guaco e o eucalipto, e outro, "as pedras no rim", para as quais se usam folhas de abacate, o chá de "quebra-pedra" ou a raiz da "grama da praia".

\section{QUADRO I}

Medicina caseira e medicina alopática, em sete localidades da Regiäo de Bauru, S.P., 1981. Plantas medicinais e seu uso, segundo a literatura $e$ as informaçōes das pessoas entrevistadas*

Nome da Planta

mencionada

1 ABACATE (folha)

2 ABORA (Cabo)

3 AGRIÃO

4 ALCACHOFRA

5 ALECRIM

6 ALFACE

7 ALFAVACA ALFAVACÃO

8 ALHO
Nome Científico $(2,3,12,13,23)$

Persea gratissima

Curcubita pepo $L$.

Nasturtium officinale

Cynara scolymus

Rosmarinus officinalis $L$.

Lactuca sativa $L$.

Ocimum gratissimum $L$. antiemético; diurético; dores; gripe;

Allium sativum $L$. febre; tosse tosse

Usos mencionados na Usos mencionados Literatura $(2,3,12$, pelos entrevistados. 13, 23)

vermífugo; diurético; rins; bexigas, estôafrodisíaco

mago.

males do fígado; pedras nos rins vermífugo

estimulante

bronquite; fortificante; úlcera gástrica

males do fígado; fígado preventivo de arterosclerose

antiespasmódico; esto- calmante: estômago; máquico; menagôgo gripe; febre

tosse; dores reumáti- calmante; gripe cas; insônia; calmante

cólicas estomacais e intestinais; estimulante da produção de leite; flatulência calmante; dores de barriga; estômago; gripe; intestino 
Nome da Planta

mencionada

9 ALPISTE

10 AMOREIRA (folha)

11 ARNICA

12 ARTEMISIA

13 ARRUDA

14 AVENCA

15 BABOSA

16 BÁLSAMO
Nome Científico

$(2,3,12,13,13)$
Usos mencionados na Usos mencionados Literatura $(2,3,12$, pelos entrevistados $13,13)$

Phalaris canaviensis $L$. não mencionado pressão

Morus migra $L$. Morus alba $L$.

antifebril; diarréias; expectorante

Amica montana L.

contusões

machucado

Artemisia vulgaris

anemia; cólicas; diarréia; menstruação deficiente; reumatismo

menstruação

atrasada

Ruto graveoelus $L$.

amenorréia; vermífugo

cólica menstrual; estômago; regular menstruação; para benzedura

Adiatum cuneatum

catarro pulmonar; rins rouquidão; tosse; laringite

queimaduras; erisipela; queda de cabelo Aloes perfoliata Aloes vulgaris Aloes bardadeusis

cicatrizante; diabetes; afecções do Myroxilon toluifera H.B.K. aparelho urinário

Myroxilon perniferun Balsamum indium nigrum

17 BANANA

Musa sp.

diurético; antiblenorrágico

bronquite

machucado; dor-de-ouvido

não mencionado

fogo bravo

diarréia;

hemorragias

barbatimum

M. mimosoideae

20 BATATA DE PURGA

Convolvulus

operculatus

purgativo; irregularidades menstruais; hemorragia nasal; enterites.

evitar calvice (JALAPA)

21 BOLDO

Peumus boldus

diurético; males do fígado

machucado

bronquite; intoxicação alimentar; verminose.

estômago; cólica; fígado

\section{Luffa operculata purgativo;} Momordica operculata expectorante

não mencionado

não mencionado

dor-de-cabeça

Zea mays $L$.

não mencionado

rim; bexiga

Coffea arábica $L$.

diurético; diabetes; estimulante SNC dor-de-barriga; veneno 
ARTIGO

Nome da Planta

mencionada
Nome Científico

$(2,3,12,13,13)$
26 CAFEZINHO DE BUGRE Cordia salicifalia

27 CAMBÄRA

28 CAMOMILA

(MARCELA)

29 CANA BRAVA

30 CANELA

31 CANELA DE VEADO

32 CÂNFORA

33 CAPIM AMARGOSO

34 CARAGUATÁ

35 CARAMBOLA (folha)

36 CAROBINHA

37 CARQUEJA

38 CARRAPICHO CARRAPICHINHO

39 CEBOLA

40 CENOURA

41 CHAPEU DE COURO

42 CHICOPINA

\section{Lantana spinosa}

\section{Achyrocline} satureoides

Anthoxanthium gigans

Cinnamomum

zeylanicum L.

não mencionado

Cinnamomum camphora

Sporobolus asperifolius

Bromélia antiacanthe

Avenhoa carambola $L$. Jacarandá pteroides

Baccharis sp

Triufetta rhomboidea

Allium cepa

Daucus carotta $L$.

Echinodorus macrophyllus

não mencionado
Usos mencionados na Usos mencionados Literatura $(2,3,12$, pelos entrevistados 13, 13)

expectorante; preven- pedras no rim tivo de arterosclerose

asma; tosse catarral; bronquite coqueluche

calmante; tônico digestivo

clarear cabelo; cólica; dor de barriga; estômago

diurétićo

pressão

antisséptico; cal- resfriado; forti-

mante; estimulante; ficante; cólicas; estomáquico; estimu- tosse; dieta lante da função digestiva

não mencionado gripe

não mencionado gripe

tosse; catarro machucado

pulmonar

não mencionado bronquite

diabetes

afecções cutâneas; doença de pele; reumatismo; úlceras; sífilis; reumasífilis tismo; úlceras

anemias; diabetes; coração; diabetes; diarréia; cálculos estômago; fígado; biliares; enfermida- reumatismo des baço; bexiga; fígado; rins

adstringente; blenor- hemorróidas; ragia; lavagem de útero; rins uretra.

expectorante; preven- rins tivo de aterosclerose

não mencionado anemia

rins; bexiga;

reumatismo

reumatismo; rins;

depurativo

não mencionado reumatismo; cólica menstrual 
Nome da Planta

mencionada

43 CHUCHU

44 CIPO CRUZ

45 CIPO SUMA

46 Côco

47 CÔCO DE DENDÊ

48 COMINHO

49 CRAMOSA (flor)

50 CRAVO

51 ERVA CIDREIRA (melissa)

52 ERVA DE BICHO (pimenta d'água, Persicária)

53 ERVA DOCE (anis)

54 ERVA MOURA

55 ERVA SANTA MARIA

56 ERVA SÃO JOÃO (mentrasto mentrasta)

57 ERVA TOSTÃO

58 EUCALIPTO
Nome Científico

$(2,3,12,13,13)$

Sechium edule

Chiococca brachiata

Anchietera salutaris

Cocos nucifera $L$.

Elaeis guineensis

Cominum cyminum

não mencionado

Dianthus caryophillus

Melissa officinalis L.

Polygonum acre

Pimpinella

anisum $L$.

Solanum nigrum

Solanum hortensis

Solanum crenato

dentatum

Chenopodium

ambrosioides $L$.

Ageratum conyzoides

. cólicas intestinais;

Boerhaavia hirsuta

Eucalyptus sp.

feridas e úlceras; diarréia

diurético; males

fígado

Usos mencionados na Literatura $(2,3,12$, 13,13 )

anti-hipertensivo; diurético

anti-reumático; diurético

sífilis; sarna;

dermatoses

diurético

anginas; cefaléias;

cólicas abdominais

dispepsias; diurético; cólicas

emenagogo; estomá-

quico; flatulências

não mencionado

contra vertigens; resfriado

cefaléia;

sudorífico

antiespasmódico;

estomáquico;

emenagôgo

hemorróidas;

provocar menstrua-

ção; verminoses.

cólicas estomacais

e intestinais; flatu.

lência; estimulante

produção/leite.

dores reumáticas;

queimaduras

combater pulgas;

carrapatos e piolhos;

verminose

bexiga; estômago;

espectorante; febre gripe

estômago

machucado;

verminoses

cólicas intestinas; aborto

rins

ARTIGO

Usos mencionados

anti-hipertensivo;

estômago;

diarréia

calmante;

estômago; febre;

gripe

hemorróidas;

pneumonia; res-

friado; reumatismo

cólicas estomacais

e intestinais; gripe;

calmante.

pele

febre; inalação;

sinusite;

obstrução nasal

Cadernos de Saúde Pública, R.J., 2 (1): 150-166, abr/jun, 1986. 
Nome da Planta mencionada

59

FEDEGOSO

60 FEIJÃO CHICOTE OU CORDA (folha)

61 FUMO

62 GOIABA

63 GRAMA DA PRAIA (Raiz)

64 GUAÇATUGA

65 GUACO

66 GUAIMBE (Raiz)

67 GUINÉ DO MATO

68 HORTELÃ

(levante)

69 IPÊ-ROXO (casca)

70 ISOPO

71 JACARATIÁ

72 ЈАТОВА̊ (casca)

73 JUQULRI

74 JUÁ BRAVO

75 I.ARANJEIRA (folha)
Nome Científico

$(2,3,12,13,13)$

Cassia occidentalis
Cassia medica

Vigna sinensis

Nicotiana tabacum $L$.

Psidium guayava $L$.

Stenotaphrum

glabrum

Casearia sylvestris

Samyda sylvestris

Mikania guaco

Mikania amara

Caladium pendulinum Caladium lacerum

Petiveria alliacea

Mentha gentilis $L$.

Tabebuia impetiginosa Tabebuia avellanedae

não mencionado

Jacaratiá dodecaphyla

Hymenaea courbaril

Solanum juceri $M$.

Zizyphus joazeiro

Citrus sinensis
Usos mencionados na Usos mencionados Literatura $(2,3,12$, pelos entrevistados $13,13)$

antifebril;

anti-sifilítica

não mencionado inchaço

não mencionado

tétano

diarréias; úlceras estomacais; inflamação garganta

diarréias; dores de barriga

diaforética

diaforética

pedras do rim pedras no rim

depurativo; hidropsia; machucado moléstias pele;

sífilis

febre; bronquite; tosse

tosse gota; paludismo; reumatismo; sífilis, diurético

afeç̧ões reumáticas reumatismo

não mencionado

Hepatite; mordida de cobra; reumatismo

cólicas intestinais; calmante; dor de excitante SNC; $\quad$ barriga; resfriado; expectorante verminose

analgésico; afecções reumatismo da pele; artrites

não mencionado dor de cabeça

hidropsia;

feridas

dor de barriga;

bronquite;

reumatismo

vermífugo; estomá- bronquite; quico; cistite aguda maleita; ou crônica; tosse; tosse bronquite

$\begin{array}{ll}\text { sífilis; } & \text { furúnculos; } \\ \text { feridas } & \text { limpar o corpo }\end{array}$

febres intermitentes furúnculo

gripes; resfriado; gripe; tosse pneumonia; calmante; $\mathrm{p} /$ sudorese 
Nome da Planta

mencionada

76 LIMA DE UMBIGO

77 LIMĀO

78 LOSNA

(erva dos vermes)

79 LOURO

80 MALVA

81 MAMOEIRO

(folha)

82 MAMONA

83 MANDACARU

84 MANGA (folha)

85 MARACUJÅ

86 MARCELINHA galega

87 MILHO DE GRILO

88 MOSTARDA

89 NOZ-MOSCADA

90 PACOVÁ

91 PAINEIRA (casca)
Nome Científico

$(2,3,12,13,13)$

Citrus limetta

Citrus limonum

Artemisia absithium L. catarros; cólicas;

diarréia; envenenamento; perturbações gástricas

Laurus nobilis $L$.

Malva sp

Kielmeyera sp

Carica papava $L$.

Ricinus communis

Cereus

hildemannianus

Maugifera indica

Passiflora quadrangularis

Antemis nobilis $L$.

não mencionado

Brassica sp

Myristica

officinale

Renealmia brasiliensis

Bombax ventricosa Literatura $(2,3,12$, $13,13)$ males do estômago; dermatoses

antisséptico; reumatismo; bronquite;gripe

amenorréia; anúria;

dispepsia;

reumatismo

calmante; catarro;

enfermidades da

garganta e ouvido

vermífugo;

auxnlio digestão

purgativo;

vermífugo

escorbuto diarréia; insônia; calmante

dor de estômago

não mencionado cólicas intestinais
Usos mencionados na

afecções renais; hepatite

ARTIGO

Usos mencionados pelos entrevistados

gripe;

para pressão

cólica estômago; cólica intestinal;

vômitos

estômago;

enxaqueca;

calmante;

fígado

tosse; gripe;

estômago

hemorróidas

lombriga

bronquite; verminose; tosse; pneumonia; diurético; estimulante dor de estômago produção leite materno

alcoolismo crônico; calmante convulsão infantil;

empachamento

cataplasma $\mathbf{p} /$ dores febre

digestão; estômago; $\quad$ gripe; tosse; acalmar vômitos; dor de estômago

vermífugo vermes

queimaduras ferida 
Nome da Planta mencionada

92 PARAFUSO

93 PARATUDO

94 PARIETÁRIA

95 PARIPAROBA (capeba)

96 PARREIRA BRAVA (flor)

97 PICÃO

$98 \begin{aligned} & \text { PINDAIBA } \\ & \text { (fruta) }\end{aligned}$

99 PITANGA (folha)

100 POEJO

101

QUEBRA-PEDRA

102 QUINA (casca)

103 ROMÃ (casca)

104 ROSA (branca)

RUBIM

SABUGUEIRO
Nome Cientifico $(2,3,12,13,13)$

não mencionado

Gomphrena

officinalis $\mathrm{M}$.

Parietdria

officinalis

Piper umbellatum

Piper sidefolium

Piper hilarianum

Piper peltatum

Piperonia umbellata

Chondodendron
tomentosum

Bidens pilosa $L$.

Xylopia

brasiliensis

Eugenia

michelli

Mentha pulegium $L$.

Phyllanthus niruri $L$.

Ogcodeia amara

Punica granatum $L . \quad$ verminose

Rosa alba $L$.

Borreira tenella

Sambucus nigra $13,13)$

renal

feridas

diurético;

maleita
Usos mencionados na Usos mencionados Literatura $(2,3,12$, pelos entrevistados

não mencionado rim

estimulante; estomá- para tudo quico; colites;

antitérmico

moléstias de vias pedra no rim

urinárias; artrite;

afecções catarrais

resfriados; queima- fígado; rins;

duras; escorbuto; anti- estômago;

blenorragia;

sangria

diurético; furúnculos;

antitérmico; moléstias

do fígado e baço

antitérmico; emena- gripe

gogo; diuréticos;

contusões; calculose

hepatite; icterícia; Hepatite

contra flatulência pontada no coração

calmante; bronquite;

febre tosse

acidez e ardor de calmante; cólica

estômago; catarro; intestinal; bron-

diarréia; irregulari- $\quad$ quite; gripe; tosse;

dade menstrual; tosse verminose

pedras no rim

rim; bexiga

dor de barriga

diarréia; dor de barriga; garganta; verminose

antisséptico local; cólica intestinal; calmante; purgante feridas; laxante

cordas vocais contusão; estômago

escarlatina; hemorrói- sarampo das; reumatismo; rubéola; sarampo 
Nome da Planta

mencionada

107

SALSA PARRILHA

108

SALTA MARTRIN

109 SAMAMBAIA-GUAÇU

110 SAPE (raiz)

111 SENE DO CAMPO

112 SERRALHA

$113^{\circ}$ SOLIDONIA

114

TRAPOERABA

115 UNHA-DE-VACA

116 UVA JAPONESA (folha)

117 XIPRE

118 ZAMUMBA (flor)
Nome Científico

$(2,3,12,13,13)$

Smilax medica

Smilax officinalis

Smilax syphilitica

não mencionado

Apidium filix mas Polypodium filix mas

Polypodium instans

\section{Imperata \\ brasiliensis \\ Cassia cathartica \\ Silybum marianum}

Boerhavia

paniculata

Tradescantia

diurética

zebrina sp.

Bauhinia aculeata

Bauhinia fortificate

não mencionado

não mencionado

Datura stramonium
Usos mencionados na Literatura $(2,3,12$, $13,13)$

dermatoses; depura- depurativo;

tivo; diurético; enfer- furúnculo;

midades venéras

sífilis

não mencionado

maleita

vermífugo

depurativo;

furúnculo

pedra nos rins

antifebril; laxante febre;gripe

hemorróidas; ingur- vermífugo

gitação útero; uretra

contra-afecções do hemorróidas

fígado e vesícula

biliar; diurético

afecções herpéticass; caimbra de sangue

diurética; acalma

comichão; (prurido

dos dartros); dores

reumáticas

diabetes

diabetes

não mencionado

não mencionado

reumatismo; con- vermífugo

falta de ar

pedras no rim

r

tusões; contra asma;

hipnótico

(*) Sugestão e orientação de: Goldfarb, E.: O Curandeiro na cidade de Jundiaí. Relatório de Pesquisa, FAPESP, São Paulo, 1983.

\section{COMENTÁRIOS}

O conhecimento e o uso difundido de plantas medicinais observados nesta pesquisa reforçam dados já conhecidos a respeito $8,10,22 *$. O estrato mais afastado dessa prática é o alto, por seu maior acesso à medicina alopática e identificação, na estrutura social, com seus representantes. Acreditase, entretanto, que o fator econômico talvez não fosse suficiente para determinar o desaparecimento da medicina *CONSORTE, J. \& VILLAS BOAS, M.H. Sistemas de saúde paralelos. Comunicação oral. 10 ? Jornada Científica da Associação dos Docentes do Campus de Botucatu - UNESP, abr. 1981. 
caseira, já que mesmo os estratos mais altos a ela ainda recorrem.

O meio de obtenção de plantas medicinais confronta o método natural com o industrializado, sendo o primeiro muitas vezes mais utilizado, principalmente no estrato baixo, dada a existência de quintal com terra, na maioria das casas; e a proximidade com áreas de vegetação silvestre.

Já o produto manipulado e comercializado na farmácia representou uma opção que, embora incipiente, traduz o efeito da "medicalização", que não poupou as plantas medi. cinais e é também incrementada pela propaganda ${ }^{25}$. Pelo método natural compreende-se o modo artesanal de preparo, ligado fortemente à tradição popular. A manipulação não deixa de ser a incorporação desse conhecimento popular por laboratórios, em sua maioria nacionais, que, marginalizados do mercado dos alopáticos pelas multinacionais da indústria farmacêutica, começam a florescer nos grandes centros urbanos ${ }^{17}$. Esta chamada industrialização marginal não possui regras ou sistemas de controle, apresentando, por isso, falhas no que concerne ao modo de colheita, transporte, manipulação e conservação. Estes cuidados e critérios do acervo da cultura popular, até certo ponto, são considerados pela ciência oficial, mas na medida em que não são observados, questiona-se a real eficácia do produto vegetal $^{10,19,21}$.

$\mathrm{Na}$ questão da indicação de plantas, a pequena taxa de vegetais sem nome científico correspondente pode ser devida à falha explicitação do nome popular, citação de um nome popular não conhecido, ou mesmo a ocorrência de plantas ainda não classificadas e/ou de efeito terapêutico obscuro. É comum encontrar, na literatura, várias denominações populares para uma mesma planta ${ }^{3,15,22}$. Por outro lado, houve alto índice de indicação coincidente com a literatura, denotando considerável difusão de seu conhecimento.

Frente à reafirmação do uso difundido de plantas medicinais neste trabalho, à pouca noção do sistema oficial a respeito deles e à escassez de investigações científicas correlatas, recomenda-se que conhecimentos populares sejam transmitidos na Universidade, como já tém ocorrido esporadicamente $^{17} \mathrm{e}$, ainda, que haja incentivo e apoio às pesquisas nesse campo, pelos órgãos e agências financiadoras competentes.

\section{AGRADECIMENTOS}

Os autores agradecem a orientação e supervisão de Cecrlia Magaldi, Professora Titular do Departamento de Medicina 
Legal e Medicina em Saúde Pública da Faculdade de Medicina de Botucatu - UNESP.

|||||||||||||||||||||||||||||||||||||||||||||||||||||||||||||||||||||||||||||||+||||||||||||||||||||||||||

The knowledge and the use of medicinal plants (MP) were investigated in 372 people interviewed in the Bauru (São Paulo) area in 1981. The majority of the people was from a low social status.

More than 95\% of the people interviewed know MP, with a high use of 2 to 4 varieties. Only 10,8\% did not use these plants. The MP are obtained at the house yard (first choice) or at the pharmacy (second choice). Almost 118 different MP were cited. From these only 9,3\% did not have a correspondent scientific name and $17 \%$ did not have pharmacological properties described in the medical literature. Almost $70 \%$ of our observations are in accordance with the literature considering at least one symptom or one disease.

The authors also discuss the reasons of the increment of domestic medicine, and some aspects of the industrial production and trade of drugs made of medicinal plants. They emphasize the necessity of pharmacological research in order to provide knowledge on the therapeutic use of the brazilian medicinal flora.

\section{REFERÊNCIAS BIBLIOGRÁFICAS}

1. AKERELE, O. Um rumo para a medicina tradicional. Saúde Mundo, 1983: 3 .

2. BALBACK, A. A flora nacional na medicina doméstica. São Paulo, Edificação do Lar, 1974. v. 2, p. 869.

3. BALBACK, A. A flora nacional na medicina doméstica. 17 ed. São Paulo, Edificação do Lar, 1974. p. 919.

4. BRASIL. Central de Medicamentos. Coordenadoria de Pesquisa. Relatório da Comissão de Seleção de Plantas. Brasilia, 1983. p. 30 , mimeo.

5. CALDER, R. $O$ homem e a medicina. Mil anos de trevas. São Paulo, Hemus, 1976. p. 22.

6. CONFERÊNCIA INTERNACIONAL SOBRE CUIDADOS PRIMÁRIOS DE SAƯDE. Alma-Ata, URSS, set. 1978. Cuidados primários de saúde; relatório. Alma-Ata, OMS, 1979. p. 64 .

7. CONFERENCIA NACIONAL DE SAÚDE, 5‥ Brasília, 1975. Anais. Brasília, Ministério da Saúde, 1975. p. 3. 
8. CUNHA, N.F. \& SABOIA, S.M.N. Ervas, uma terapêutica no campo da enfermagem. $R$. bras. Enferm. 34: 269, 1981.

9. EPM pesquisa as plantas medicinais. Folha de São Paulo, 22 jan. 1983.p. 20.

10. FERRARI, B. A redescoberta das plantas medicinais. $R$. bras. Clin. Terap., 13: 309, 1984.

11. FOSSAT, A.G. A cura pelas plantas. 4 ed. Rio de Janeiro, Eco, s.d. p. 159.

12. FUNDAÇÃO INSTITUTO BRASILEIRO DE GEOGRAFIA E ESTATISTICA. Sinopse preliminar do curso demográfico: Brasil ; 9 \% recenseamento geral do Brasil 1980. Rio de Janeiro, 1981.v. 1, t. $1, \mathrm{n}$ ? 18

13. FUNDAÇÃO INSTITUTO OSWALDO CRUZ. Politica de investigação em saúde no Brasil. Relatório. Rio de Janeiro, 1981. p. 72, mimeo.

14. GEMTCHÚJNICOV, I.D. Manual de taxonomia vegetal. São Paulo, Ed. Agronômica CERES, 1976. p. 368.

15. LAINETTI, R. \& BRITO, N.R.S. A cura pelas ervas e plantas medicinais brasileiras. Rio de Janeiro, Tecnoprint, 1979. p. 169.

16. MARCONDES, E. et alii. Estudo antropométrico de crianças brasileiras de zero a doze anos de idade. An. Nestlé, 84:47, 1968. (número extraordinário).

17. MEDICINA popular resgata seu prestígio. Folha de São Paulo, 11 nov. 1984 p. 27.

18. MOREIRA, M.F. O CNPq e o programa de pesquisas em produtos naturais. Ci. e Cult., 32 (supl.): 217, 1978.

19. MORS, W. Plantas medicinais. Ci. Hoje, 3: 14, 1978.

20. DE LA PENHA, G.M. A FINEP e o programa de pesquisas em produtos naturais. Ci. e Cult., 32 (supl.): 217-20, 1978.

21. PLANTA medicinal, um comércio sob suspeita. Folha de São Paulo, 22 maio 1983. p. 26.

22. RAVAGNANI, O.M. Medicina popular no estado de São Paulo. Araraquara, 1981. [Dissertação de mestrado - Instituto de Letras, Ciências Sociais e Educação - UNESP].

23. SIMPOSIO DE PLANTAS MEDICINAIS DO BRASIL, 5‥ São Paulo, 1978. Ci. e Cult., 32 (supl.) 1978.

24. SIMPOSIO DE PLANTAS MEDICINAIS DO BRASIL, 6‥ Fortaleza, 1980. Ci. e Cult., 33 (supl.), 1980.

25. TEMPORÃO, J.C. \& RAMOS, C.L. A propaganda de medicamentos e o mito da saúde. Saúde em Debate (11): 33, 1981. Cadernos de Saúde Pública, R.J., 2(2):150-166, abr/jun, 1986 